\title{
Jesus histórico e a América-Latina:desenvolvimento e contribuições em meio à Teologia Latino-Americana
}

\author{
Historical Jesus and Latin America: development and contributions in the midst \\ of Latin American theology
}

\author{
Mateus Soares Guedes* \\ Flávio Schmitt* \\ doi) $\underline{\text { https://doi.org/10.29327/256659.12.2-16 }}$
}

Resumo:

O presente artigo investiga como a Teologia Latino-americana vê o Jesus histórico e constrói sua teologia a partir dele, além de observar as implicações para a sociedade. Para tanto, faz-se necessário entender o que é esse Jesus Histórico. Entende-se o Jesus Histórico como um resultado da pesquisa científica a partir de interdisciplinaridade, que é característica da terceira fase da pesquisa sobre Jesus, a third quest. Assim, observa-se que a Teologia Latino-Americana, acolhe os resultados dessa pesquisa sobre Jesus e a partir disso constrói sua teologia, tendo uma tarefa importante, discutir fé e história. Dessa forma, os teólogos latino-americanos entenderam que o Jesus Histórico é a base da fé, de tal modo que o ponto de partida para uma cristologia latino-americana deve ser o Jesus histórico. Assim, a partir da observação histórica de Jesus, compreende-se Jesus em meio a um contexto de opressão e injustiças, o qual aplica a sua mensagem para esses contextos. Considerando que a mensagem e vida de Jesus está permeada por diversos aspectos sociais, econômicos, políticos e ideológicos, a teologia apresentada na América Latina também deveria estar envolvida em uma luta contra a opressão e injustiça social, já que o contexto político-social da América Latina está permeado por diversos tipos de opressão, exploração e injustiças.

Palavras-chave: Jesus histórico. Teologia Latino-americana. Sociedade.

\section{Abstract:}

This article investigates how Latin American theology sees the historical Jesus and builds his theology from it, as well as observing the implications for society. To do this, it is necessary to understand what this Historical Jesus is. The Historical Jesus is understood as the result of scientific interdisciplinary research, which is characteristic of the third phase of the research on Jesus, the third quest. Thus, it is noted that Latin American theology welcomes the results of this research on Jesus and from this builds his theology, having an important task, discussing faith and history. In this way, Latin American

\footnotetext{
*Graduado em Teologia pela Faculdade Teologia Batista Equatorial; Mestrando em Tradições e Escrituras Sagradas pela Escola Superior de Teologia (EST), como bolsista CNPq. Email: mateussguedes@outlook.com.

** Doutor em Ciências da Religião pela UMESP, professor na Faculdades EST em São Leopoldo/RS. E-mail: flavio@est.edu.br.
} 
theologians will understand that the Historical Jesus is the basis of faith, so the starting point for a Latin American Christology must be the historical Jesus. Thus, since the historical observation of Jesus, Jesus is understood during a context of oppression and injustice, which applies his message to these contexts. Considering that the message and life of Jesus is imbued with various social, economic, political, and ideological aspects, the theology presented in Latin America must also be involved in a fight against oppression and social injustice, since the political and social context of Latin America is imbued with various types of oppression, exploitation, and injustice.

Keywords: Historical Jesus; Latin American theology; Society.

\section{Introdução}

Falar de Jesus histórico é uma tarefa perigosa, porém necessária. Por um lado, há o perigo da cansativa repetição, já que se trata de um tema que é pesquisado desde o século XVII. Dessa forma, trabalhar um tema que perpassa ao menos cinco séculos, de muita pesquisa e discussão, é um desafio muito grande para que não se caia na repetição enfadonha do tema, ou para que não se enquadre na afirmação de D. Crossan: "a pesquisa do Jesus histórico está virando uma piada acadêmica sem graça”(CROSSAN, 1994, p. 26). Por outro lado, há uma necessidade muito grande dessa pesquisa, pois é a partir dela que existe a possibilidade de uma construção mais próxima de quem de fato foi Jesus de Nazaré, e de uma teologia próxima a pessoa histórica de Jesus e seu movimento.

Algumas perguntas, contudo, são suscitadas desde agora, e que perpassarão pelo presente artigo. Entre elas, é necessário indagar se após vários anos de pesquisa no tema, ainda há necessidade da pesquisa do Jesus histórico, além de nos perguntarmos a necessidade desse Jesus histórico para a teologia latinoamericana. Clifford Geertz, afirma: "à medida que o homem muda, muda também o mundo do senso comum, pois ele é visto agora como uma forma parcial de uma realidade mais ampla que o corrige e o completa" (GEERTZ, 2008, p. 89). De tal modo, é inegável que os tempos, desenvolvimentos e condições sociais moldam as pessoas e suas visões de mundo, e consequentemente o pesquisador e a pesquisadora, afetando assim a própria pesquisa.

Esse fato é visto ainda mais na própria acusação de Albert Schweitzer (2003) aos teólogos liberais que o antecederam e que tiveram um papel importante, em sua época, na pesquisa do Jesus histórico. Para ele, a pesquisa desses teólogos refere-se muito mais aos frutos de suas obstinações do que um propósito maior de encontrar o verdadeiro Jesus histórico. Ou, em outras palavras, o caráter projetivo das imagens da vida de Jesus estava de acordo com os seus autores (THEISSEN; MERZ, 2002, p. 24).Dessa maneira, levando em consideração a 
constante mudança e evolução da humanidade, inclusive na pesquisa científica (métodos, materiais e descobertas), pode-se afirmar que sempre haverá uma necessidade de uma revisão ou uma nova busca pelo Jesus histórico.

Em outras palavras, apesar de anos de pesquisa sobre o tema, ele se faz inesgotável. Pedro Ramão Hilgert (1987), por exemplo, entende que o Jesus histórico é "renovado" de tempos em tempos exatamente porque os tempos demandam a compreensão de sua pessoa e missão, e por isso essa busca não cessa. Ou seja, a pesquisa do Jesus histórico, apesar da produção escrita tratando sobre o tema, se faz necessária a partir de uma "nova realidade" vivida nos tempos atuais.

Com base nas afirmações postuladas anteriormente, é importante pensar sobre um Jesus histórico no âmbito latino-americano, além de relacioná-lo não somente com a teologia, mas também com a sociedade. Se a visão de mundo, o ambiente e a posição social de uma determinada maneira moldam a pesquisa, é importante entender as relações da teologia latino-americana com a pesquisa do Jesus histórico, além disso, observar as implicações dessa relação para a sociedade.

Esse artigo, portanto, pretende discutir as relações que a teologia latinoamericana possui com essa pesquisa sobre o Jesus Histórico e as implicações para a sociedade na América Latina. Para tanto, três passos serão desenvolvidos: 1) Tentar-se-á definir o que é a pesquisa do Jesus histórico e onde a mesma ocorre; 2) Apresentar como a TLA, ${ }^{1}$ pensa Jesus histórico e como ela o desenvolve; 3) Discutir as contribuições desse foco tanto para a pesquisa como para a sociedade.

Para tanto, alguns autores se fazem importantes na pesquisa tanto do Jesus histórico como na discussão da Teologia Latino-Americana. Sobre o Jesus histórico, a pesquisa passa pelos nomes de Albert Schweitzer, Dominic Crossan, Wolfgang Stegemann, Gerd Theissen e John Meier. Já em relação aos desenvolvimentos na América Latina tanto em termos de teologia como de sociedade a presente pesquisa tem por base Maria Clara Bingemer, Rubem Alves, Gustavo Gutierrez, Jon Sobrino, Jessé Souza e Eduardo Galeano.

Dessa forma, portanto, não se pretende somente explanar os diversos comentários, ou teologias, sobre Jesus, feitos por teólogos latino-americanos baseados no Jesus histórico. Mas, o objetivo é procurar refletir sobre o desenvolvimento e as contribuições da TLA a partir do Jesus histórico. 


\section{Jesus Histórico: lugar e definição}

O termo Jesus histórico é um termo bastante abrangente, especialmente quando se trata sobre a sua pesquisa. Para dar um exemplo do panorama da discussão, é possivel mencionar que o próprio nome "Jesus histórico" é questionado para referir-se a essa pesquisa. Outras possibilidades como o "Jesus real" utilizado por Gerd Lüdemann e Klaus Berger ${ }^{2}$, e em uma discussão mais recente, o Jesus lembrado, expressão trazida especialmente por James Dunn (2003), fazem parte deste universo.

A dimensão desta pesquisa ainda pode ser vista em relação ao tempo e sua abrangência disciplinar. Esse tema possui um longo período, sendo iniciado no século XVII através de H. S. Reimarus e perdurando até os dias atuais. Diante disto, pode-se entender, como uma possibilidade de divisão, três fazes, cada qual com suas características e com seus representantes ${ }^{3}$.

A first quest, de acordo com Stegemann (2012, p. 107), desenvolveu-se durante o período de 1778-1906. Já para Theissen e Merz (2002, p. 21-24) de 196419104. Esse período é marcado pela pergunta sobre a autêntica historicidade de Jesus, ou seja, ou puramente histórico ou puramente sobrenatural. É nesse período que o evangelho de João começa a não ser considerado uma real fonte histórica, por David. F. Strauss (1808-1874).

Já a second quest, é envolvida por uma discussão maior que se resume a entender se o período de 1906-1973, pode ser considerado como uma pesquisa sobre o jesus histórico. Para alguns autores, esse período é considerado como um colapso da pesquisa sobre Jesus (THEISSEN; MERZ, 2002, p. 24), ou simplesmente como um período em que não houve pesquisa sobre Jesus (STEGEMANN, 2012, p. 107), tendo como um dos pesquisadores principais R. Bultmann. Todavia, apesar da "falta de material" é possivel concordar com Marsh (1997), citado por Stegemann (2012, p. 108):

Pela história da procura (por Jesus) fica claro que - estritamente falando - não existiu algo assim como um período de não procura, mas só um periodo que o caráter das fontes disponíveis foi radicalmente questionamento e a criatividade das primeiras comunidades cristãs foi acentuada [...].

Assim, dentro do período da second quest pode-se considerar o período em que alguns pesquisadores entendem que não houve busca pelo Jesus histórico. 
De tal modo, essa fase da pergunta sobre Jesus é marcada primeiramente pela pesquisa histórica de Jesus que se encontrava mais na retaguarda da exegese do Novo Testamento, e pela procura da conciliação entre a mensagem querigmática e a história de Jesus. Assim, enquanto a primeira fase foi marcada por uma forte oposição para com a mensagem da igreja, na segunda fase há uma tentativa de conciliação ${ }^{5}$.

A terceira fase, ou seja, a third quest, iniciou-se em 1973 e se estende até os dias atuais. É preciso ter em mente, desde já, como uma de suas principais características, que está fase está envolvida por uma transdisciplinaridade, o que supõe não só a necessidade da pesquisa, mas também sua importância, estando relacionada à história, sociologia, antropologia, teologia e, como uma das principais caraterísticas da third quest, arqueologia.

Embora, geralmente se pense que Jesus é um tema exclusivo da teologia, a terceira busca sobre o Jesus histórico, mostrou a importância do diálogo da teologia com outras ciências sociais e históricas, sendo um dos grandes avanços dessa pesquisa. Entrementes, a thirdquest mostra como a Teologia atua, ou até mesmo depende, dentro e das demais ciências sociais, ou seja, a Teologia deve ser pensada em meio as ciências sociais. Em outras palavras, "poderíamos dizer que não existe uma Teologia, a não ser numa determinada realidade social com suas complexidades específicas" (HILGERT, 1987, p. 40). A relação que os teólogos latino-americanos fizeram a partir do Jesus histórico comprova isso.

Um lado importante dentro dessa nova "atuação", a partir das demais ciências, é que a teologia passa por uma revisão e adequação de sua metodologia, ou seja, são repensados e aperfeiçoados os métodos exegéticos utilizados pelos teólogos, especialmente ao que tange o método histórico-crítico, método esse que foi influenciado pelo iluminismo, e teve alguns de seus princípios formulados no final do século XIX, pelo teólogo alemão Ernst Troeltsch (WEGNER, 1998, p. 31). Assim:

\footnotetext{
A terceira procura por Jesus encontra-se especialmente marcada também por novas abordagens metodológicas no contexto e em complemento ao elenco dos métodos tradicionais da crítica histórica. [...] Ao lado da metodologia histórica-religiosa, eles empregam também ofertas metodológicas e modelos antropológico(culturais), sociológicos e sócio-históricos, e a arqueologia da Terra Santa. Essa orientação interdisciplinar é típica para a thirdquest (STEGEMANN, 2012, p. 51).
} 
Entende-se, dessa maneira, onde atua a pesquisa sobre o Jesus histórico: não somente em uma disciplina, mas em uma perspectiva interdisciplinar, em busca do "histórico-crítico-social". Diante de tudo isso, é importante compreender o que é esse "Jesus histórico".

John Meier faz uma interessante afirmação em seu livro sobre esse tema: "O Jesus histórico não é o Jesus real. O Jesus real, não é o Jesus histórico" (MEIER, 1992, p. 31). Ao fazer essa afirmação, Meier está tratando sobre uma importante distinção entre a ideia de real e de histórico. Para ele, real refere-se a um certo tipo de completude do ser, nesse caso, da pessoa de Jesus, o que, segundo ele, é impossível alcançar. É valido esclarecer que essa afirmação está diretamente ligada à discussão das fontes, e não sobre a existência ou não de Jesus. Assim, essa conclusão é baseada no fato de "as fontes de informação que subsistiram não registraram e nunca procuraram registrar todos ou mesmo a maioria dos atos e palavras do seu ministério público - sem falar do resto da sua vida" (MEIER, 1992, p. 32).

Esse fato leva a um questionamento ainda maior: se as fontes não tinham o objetivo de apresentar tudo sobre Jesus, como elas devem ser analisadas? Assim como a pergunta por Jesus, essa também não é uma pergunta nova, na realidade é nessa pergunta que está baseada boa parte da pesquisa. Em primeiro lugar ressalta-se que a maneira de olhar e pesquisar a fonte $Q$, evangelhos intracanônicos, evangelhos extracanônicos, testemunho da igreja, oralidade, perpassam a base da pesquisa sobre o Jesus histórico. E em segundo lugar, o questionamento sobre o que de fato é autêntico ou não traz à luz novas perguntas.

Aqui surge um paradoxo que, até que a arqueologia bíblica se desenvolva com novas descobertas, ou até mesmos novos escritos sejam descobertos, acompanhará os pesquisadores e pesquisadoras nessa área. Alguns critérios surgiram para que haja a identificação sobre a autenticidade dos ditos e feitos de Jesus. Para dar um exemplo dois critérios podem ser mencionados. O critério da dissimilaridade, que em resumo, entende que o que é autêntico é tudo aquilo que não pode ter sido criado pelo judaísmo ou pelo cristianismo primitivo; e o critério da plausibilidade, que entende que é autêntico aquilo que pode ser entendido à luz do contexto judaico ${ }^{6}$.

O grande paradoxo está no fato de existir critérios para identificação de autenticidade histórica sobre Jesus, mas ao mesmo tempo, esses critérios pode- 
rem levar a alguns entendimentos diferentes, que podem moldar o entendimento sobre Jesus em pequena ou larga escala. Stegmann resume bem esse fato: "praticamente cada pesquisador e pesquisadora de Jesus compila sua própria coletânea de palavras e ações autênticas de Jesus" (STEGEMANN, 2012, p. 163). Assim, mesmo que se possa fazer mais afirmações no atual momento da pesquisa, ainda assim, como afirma Crossan, corre-se o risco de ter um retrato diferente para cada exegeta (Crossan, 1994., p. 27).

Dessa maneira, Jesus histórico é uma construção científica, histórica e exegética. Dunn, resume isso da seguinte maneira: "O Jesus histórico é, corretamente falando, uma construção do século XIX e XX, usando dados fornecidos pela tradição sinótica, não o Jesus daquela época e não uma figura da história que podemos usar realisticamente para criticar o retrato de Jesus na tradição sinóptica" (DUNN, 2003, p. 126). ${ }^{7}$ Logo, ao tratar sobre a relação do Jesus histórico com os teólogos e teólogas na América Latina, refere-se a como eles e elas se relacionaram e utilizaram dessa pesquisa para uma construção teológica.

Portanto, o Jesus histórico é fruto do processo de uma construção científica, baseado em seu lugar, ou seja, na interdisciplinaridade. Assim, o Jesus histórico é um construto da ciência histórica, um resultado de trabalho científico, uma grandeza produzida discursivamente sobre a base de [mais de] um sistema de saber ou de ciência[s] específico[s] (STEGEMANN, 2012, p. 129). ${ }^{8}$

\section{Fé e história, Principio da teologia na AL}

Fé e história são temas que perpassam as mais variadas sociedades e religiões. A fé é vista dentro e através da história. É importante ressaltar que desde o início da pesquisa do Jesus histórico, especialmente na firstquest, essa é uma relação desafiadora. Reimarus, por exemplo, procurou fazer a distinção entre a pregação autêntica de Jesus e a fé dos apóstolos. David Strauss (1808-1874), retira o evangelho joanino do campo histórico e o coloca plenamente no campo querigmático, além de aplicar o conceito de mito ao Novo Testamento (THEISSEN; MERZ, 2002, p. 21-22).

Juan Luis Segundo, faz uma afirmação importante sobre fé. Embora ele não esteja falando de fé religiosa, que é o que será tratado aqui, e sim de uma fé antropológica, ele entende que a fé é pertencente a todo ser humano. "[...] a fé aparece como uma dimensão antropológica, ou seja, própria de todos [e todas], e 
de cada um dos homens [e mulheres]" (SEGUNDO, 1997, p. 17). Esse fato é importante na própria análise de fontes de Jesus. Dentro da análise das formas, que pretendia alcançar o Jesus histórico chegando até a fonte mais antiga, houve o reconhecimento de sua impossibilidade.

Essa impossibilidade se deu porque, de acordo com Stegmann, a análise das formas pode chegar somente à tradição mais antiga sobre Jesus, ou seja, "só até declarações que já sempre se encontravam entrelaçadas com a fé das comunidades mais antigas" (STEGEMANN, 2012, p. 171). Assim, até mesmo as tradições orais mais antigas continham em seus relatos a fé da comunidade que as transmitiam.

Dessa maneira, a relação fé e história vai desenvolver um papel significativo na construção de uma TLA. Não se pretende aqui discutir fé e história em relação à fonte, mas sim, entender a relação que fé e história possuem para o desenvolvimento de um olhar teológico para Jesus, ou até mesmo de uma "nova" fé em Jesus, olhar esse, enfatizado pelos teólogos latino-americanos. Boa parte das argumentações que serão apresentadas abaixo terão como base o livro de Jon Sobrino: Jesus Liberador (1991). ${ }^{9}$

\section{Fé e história sobre Jesus}

Jon Sobrino faz uma importante constatação sobre a relação entre fé e história, especialmente em relação ao conhecimento de Jesus. Para ele, Jesus Cristo é uma totalidade que possui dois lados. Um lado histórico (Jesus) e um lado transcendente (Cristo) (SOBRINO, 1991, p. 59-60). Logo, uma fé autêntica em Jesus não é somente uma fé que leva em consideração o lado transcendental, mas também o lado histórico. Ainda mais que esta fé está baseada na pessoa histórica de Jesus. Assim, Sobrino adverte que a fé em Cristo deve estar envolvida, do começo ao fim, na história (SOBRINO, 1991, p. 60).

Esse ponto leva Sobrino a fazer um importante questionamento sobre declarações de fé em Jesus. Para ele, as declarações de fé exercidas hoje estão moldadas, em sua maioria, por uma transcendência, ou o que ele chama de "afirmações-limite”. Em resumo, há nessas declarações dois lados, um lado divino e um humano. Contudo, o lado divino é sempre priorizado. Ou seja, as afirmações de fé em Jesus estão mais baseadas em sua divindade do que em sua história, e em alguns casos, somente divinalmente. 
É possivel observar um interesse acentuado nas afirmações teológicas, trazidas especialmente pelo apóstolo Paulo, sobre Jesus para sua construção teológica, ou cristológica. Assim, é enfatizada uma procura por entender Jesus mais a partir dos títulos de fé concedidos a ele pelos primeiros cristãos, tais como Filho do Homem, filho de Deus, Senhor, sumo-sacerdote, e Cristo, do que pela sua vida e ensino em meio a sociedade judaica, da qual ele fazia parte.

Esse aspecto pode ser visto, por exemplo, em uma das mais influentes obras sobre cristologia do Novo Testamento. Na obra, cristologia do Novo Testamento, de Oscar Cullman (2008), o autor divide o seu livro em quatro partes, mais a introdução. Dessa divisão somente a primeira parte e a introdução possuem algo de história de Jesus. Contudo, essas partes estão mais voltadas para a visão que os judeus e cristãos tinham de Jesus, do que para Jesus e sua obra como fundamento da cristologia. Enquanto isso, todos as demais partes voltamse para os títulos cristológicos e transcendentais dados a Jesus pelos primeiros cristãos.

É importante ressaltar, que não há uma crítica aos títulos divinais, ou a divinização de Jesus. Pela fé, acredita-se na divindade e senhorio de Jesus. Contudo, o ponto a ser entendido é "afirmar que Jesus é o Cristo, que é a expressão de o verdadeiramente divino e verdadeiro humano, são afirmações limites que, por sua natureza, exigem um caminho de conhecimento" (Sobrino, 1991, p. 60). ${ }^{10}$

Esse caminho de conhecimento passa pelo Jesus histórico. Essa relação pode ser bem entendida a partir de Sobrino que mostra como história e teologia em relação a Jesus devem ser entendidas. Primeiramente, de acordo com ele, não é possivel teologizar Jesus, ou entender a teologia de Jesus, sem primeiramente compreender e adentrar na sua vida, prática, significação social, luta social etc. E em segundo lugar, aprofundando a compreensão de Jesus, não é possivel historizar a Jesus sem também teologizá-lo, sem apresentá-lo como a boa notícia de Deus. ${ }^{11}$

Dessa forma, história e fé para a teologia latino-americana não são mutuamente excludentes. A fé em Jesus, e as compreensões de fé, inclusive a sua cristologia do alto e toda sua ação pós ascensão, devem ser entendidas a luz do que realmente foi Jesus. O Jesus histórico é o ponto de partida de uma construção teológica na AL. Assim, o Jesus histórico é articulador da fé, das confissões de fé e dos atos de fé. Desse modo, compreender a mensagem do Jesus histórico, 
permite um fundamento para uma teologia latino-americana, que levará à uma cristologia, que faça diferença não só na igreja, como também na sociedade.

É diante disso, que Hilgert atesta:

Na questão do Jesus histórico estão implicados elementos cristológicos fundamenteis sempre e em qualquer lugar, mas cuja recuperação é particularmente urgente para a fé da Igreja latinoamericana, diante das cristologias tradicionalmente veiculadas nos manuais de piedade popular e diante das grandes opções pastorais a que se interpela (HILGERT, 1987, p. 74).

\section{Foco e desenvolvimento da teologia latino-americana a partir da relação fé- história}

A partir do entendimento de como teólogos latino-americanos relacionam fé e história, como no caso de Jon Sobrino, é importante observar qual o seu foco e quais são seus desenvolvimentos teológicos a partir dessa compreensão. Mas antes de aprofundar no assunto, é necessário compreender um dos principais desafios da TLA, embora, este assunto seja mais detalhado no próximo tópico.

Os desafios principais da Teologia Latino Americana iniciam-se na compreensão do problema do mundo. Sendo uma teologia, compreende o problema geral como "pecado", todavia, esse pecado gera problemas específicos, fundamentados especialmente em uma visão sociológica. Assim, para a TLA o mundo tem pecados sociais estruturais ${ }^{12}$ (CARVALHO; PY, 2017, p. 343). Neste sentido a autora Maria Clara Bingemer, resume bem um dos principais desafios sociais da TLA:

O que significa ser cristão em um continente de pessoas pobres e oprimidas? Estavam em jogo uma teologia alinhada à prática pastoral de uma igreja que queria se fazer livremente pobre, que se colocava ao lado do pobre, e que se comprometia com a libertação de todas as formas de opressão e marginalização (BINGEMER, 2017, A igreja do Concílio Vaticano II e a teologia latinoamericana)

A opressão presente nos países latino-americanos foi catalizadora para uma visão sobre uma nova necessidade teológica. Assim, é possível perceber uma grande diferença entre produções europeias e norte-americanas e produções latino-americanas. Como Bingemer deixou claro anteriormente, a América Latina viu-se necessitada de uma teologia pastoral, de uma teologia aplicada às necessidades cruciais do povo latino-americano. 
O desenvolvimento de uma aplicação teológica aconteceu a partir do próprio Jesus histórico, e como já visto antes, a partir da compreensão social do povo, o que fez com que os teólogos latino-americanos buscassem compreender a realidade social a partir das ferramentas proporcionadas pelas ciências sociais (HIGUET, 1989, p. 47). Diante disso, o caminho que a TLA segue, é tanto a de uma construção cristológica a partir do Jesus histórico, e essencialmente uma cristologia aplicada às necessidades do povo latino.

Entender o porquê de Jesus ser o caminho para uma cristologia latinoamericana não é difícil. Em resumo, na pessoa de Jesus e em sua posição social encontrou-se uma intrinseca proximidade nas relações politicas, sociais, e antropológicas dos homens e mulheres que vivem na América Latina. Dessa maneira, Sobrino esclarece que nos últimos 20 anos de pesquisa (período da década de 70-90) as reflexões cristológicas estão envoltas do Jesus histórico, além de mostrar como os principais nomes da TLA, tais como Gustavo Gutierrez e Leonardo Boff, criticaram uma cristologia sem história, ou tão somente sobrenatural, e voltaram-se a apresentar uma cristologia a partir do Jesus histórico (Sobrino, 1991, p. 71).

Assim, Gutierrez destaca:

Aproximar-se ao homem Jesus de Nazaré no qual Deus fez-se carne, indagar não somente por seu ensino, e sim por sua própria vida, que é o que dá a sua palavra contexto imediato e concreto, é uma tarefa que se impõe cada vez com maior urgência (GUTIÉRREZ, G. 1971 apud SOBRINO, 1991, p. 71).

A partir dessa urgência, os teólogos latino-americanos procuraram, portanto, produzir teologias que estão comprometidas com o Jesus histórico. Dessa forma, entender Jesus como um judeu, nascido em Nazaré, que como carpinteiro vivia à margem da sociedade, sofrendo exploração do império romano, e através disso possuindo uma mensagem a favor da vida e das minorias, e expressando a necessidade de justiça social, contra formas de intolerância, preconceitos, hipocrisias religiosas, patriarcalismo e exploração econômica, concedeu à TLA um de seus principais termos: libertação.

É a partir desta compreensão que Gutierrez expressa por exemplo, que uma espiritualidade da libertação deve ser uma vivência que leva à comunhão com o Senhor e com todos os homens, e isso, é um dom (GUTIERREZ, 1972, p. 
269). Assim, o Jesus histórico, para os teólogos latino-americanos, é a base de uma cristologia. Logo:

A cristologia latino-americana retoma propriamente o mesmo "método", coloca-se comunitariamente diante do Senhor histórico e ressuscitado e pergunta-se por seus compromissos e esperanças diante de hoje de sua própria vida comunitária e diante dos desafios históricos a que o Senhor a envia (HILGERT, 1987, p. 70).

Entender a necessidade de uma construção cristológica a partir do Jesus histórico é algo fundamental para o desenvolvimento da TLA. Contudo, os teólogos latino-americanos não procuraram construir teologias tão somente teóricas, mas uma de suas principais características é a aplicação dessa teologia à sociedade. Assim, muito mais que apresentar uma história de Jesus de Nazaré como base de uma construção cristológica, a teologia latino-americana se propôs a apresentar uma história de Jesus de Nazaré para o nosso ser cristão, e como Hilgert assevera, dentro da história concreta do continente latino-americano (HILGERT, 1987, p. 62).

Rubem Alves compreende isso como um dos principais fatores, e pontos de partida para a Teologia Latino-Americana. Segundo ele, é preciso que a teologia na América Latina deve partir de uma nova "linguagem", assim: "a necessidade dessa nova linguagem se derivava do compromisso concreto de muitos cristãos [e cristãs] com a tarefa de tornar o homem historicamente liberto dos poderes que o mantêm escravizado" (ALVES, 1987, p. 215).

Teologia da libertação, teologia da missão integral, teologia feminista, para citar alguns exemplos de teologias latino-americanas, não são teologias com perspectivas somente teóricas. Há, obviamente, um grande esforço acadêmico por parte dos teólogos latino-americanos, não somente por meio da teologia, mas em conjunto com outras ciências sociais de interpretação tanto de sua sociedade e contexto, a partir de métodos sociológicos e antropológicos, como uma interpretação bíblica, destacando-se o método histórico social.

Contudo, esses mesmos teólogos procuram avançar saindo do campo teórico e chegando ao campo prático. Em outras palavras, o objetivo dos teólogos latino-americanos é proporcionar uma teologia que faça a diferença em meio a opressão, desigualdade e injustiça vivenciados em sua sociedade. Dessa forma, "é o contexto de opressão e dependência em todos os níveis da vida, despertando 
o seu correlato oposto - a libertação - que propicia à cristologia na AL pensar e amar a Jesus Cristo como Libertador.” (HILGERT, 1987, p. 142).

Mais uma vez, isso está pautado no próprio Jesus histórico. O autor de Mateus, a partir de uma fonte exclusiva, mostra que Jesus associava justiça social a entrada no reino dos céus. Segundo Jesus, aqueles que serão benditos, são aqueles que lhe deram de comer enquanto passava fome, de beber enquanto passava sede, o hospedaram quando era forasteiro, enquanto estava nu o vestiram, preso foram-lhe ver, e isso é feito à Jesus quando praticado aos "pequeninos" (Mt 25.34-40).

Logo, para a TLA, é necessária uma teologia que esteja pautada, especialmente, no princípio de justiça social. Libertar o oprimido e a oprimida, opondo-se ao opressor e a opressora, seja ele uma pessoa ou o sistema. Dessa forma, faz-se necessário uma aplicabilidade teológica, que passa de conceitos sobre fé, e avança para uma prática de fé. A TLA, à luz das palavras de Hilgert, quer comprometer-se com a libertação dos oprimidos e oprimidas e com a criação de uma nova história, ao menos mais próxima do plano de Deus. Plano esse, vale ressaltar, que além da libertação do pecado, volta-se para a justiça social no meio da sociedade atual.

\section{TLA e sociedade}

Teologia da libertação, teologia da missão integral, teologia feminista, teologia negra etc. são teologias que perpassam e se destacam na América Latina, embora nem todas tenham sido iniciadas no contexto latino-americano. Todas possuem contribuições fundamentais em seus desenvolvimentos em solos latinoamericanos e se apresentam necessárias no contexto referido.

Como visto anteriormente, essas teologias possuem uma preocupação essencial nos tempos e contextos atuais: uma preocupação com pessoas, seu modo de vida, seus desenvolvimentos sociais, suas lutas e vitórias. Isso vem baseado no Jesus histórico, ou seja, a compreensão de que Jesus em seu tempo possuiu essa preocupação e sua mensagem era uma mensagem que alcançava as pessoas, especialmente as pessoas oprimidas econômica, social e religiosamente.

Assim, a mensagem e vida de Jesus se voltava para os pobres e marginalizados na sociedade, se voltava para os "pecadores"que eram excluídos pelos líderes dos principais grupos judaicos, se voltou não para as grandes cidades, mas para as vilas onde a opressão econômica causada pelo império romano era mai- 
or, concedeu voz e agregou a seus grupos mulheres em meio a uma sociedade plenamente patriarcal.

As teologias latino-americanas, a partir disso, trazem uma teologia para as pessoas que se faz essencial no contexto latino-americano. Isso pode ser visto, por exemplo, na decisão feita na reunião de Medellín em 1968, que definiu que: pri-meiro, deveria haver uma conexão entre evangelização e luta contra injustiça social; segundo, a teologia deveria estar conectada com a realidade social e política de seu contexto; e por fim, as comunidades eclesiásticas deveriam se inspirar na Bíblia para transformar as condições sociais injustas (Bingemer, 2017: Os pobres como berço de trabalho teológico para a Teologia da Libertação e para a Teologia Feminista). Mas por que isso é tão importante para a América Latina?

A resposta provém tanto da história quanto da atualidade. Em primeiro lugar, é preciso relembrar que o "início" da América Latina foi marcada por grande exploração. Essa exploração deu-se em diversos aspectos, mas entre eles, estava a ganância europeia. Eduardo Galeano, apresenta a ideia que perpassava as mentes europeias chegadas na América: "Porque do ouro se faz tesouro, e quem o tem faz o que quiser no mundo e até leva as almas para o Paraíso" (GALEANO, 2012, p. 15).

A partir dessa afirmação de Galeano, pode-se perceber como a busca pela riqueza, e vale ressaltar o aspecto religioso que apresenta essa riqueza sendo capaz de levar até o paraíso, influenciou todo o início de opressão imposto pelos europeus aos autênticos latino-americanos. Além disso, retirar nesse período a Europa se desenvolvia a partir das riquezas encontradas nas américas. Como assevera Galeano: "Os metais arrebatados aos novos domínios coloniais estimularam o desenvolvimento europeu e até se pode dizer que o tornaram possivel" (GALEANO, 2012, p. 25).

Haja vista essas afirmações percebe-se que o povo latino-americano desde a chegada dos europeus viveu sobre opressão. O que é necessário ressaltar neste momento é que essa opressão não se extinguiu, mas evoluiu juntamente com a evolução que a sociedade passa constantemente. Nesse caso, hoje a afirmação de Galeano de que a América era um negócio Europeu (GALEANO, 2012, p. 26), não precisa ser excluída, apenas atualizada, isso leva ao segundo entendimento.

Todo esse processo e espírito ganancioso e consequentemente opressor, visto no "início" da história das américas, perpassou a história e é presente ainda hoje. Contudo, como mencionado anteriormente, isso não se dá da mesma ma- 
neira, mas é visto especialmente em meio a pobreza econômica e cultural que é consequência dessa opressão, e o que deve chamar a atenção, não é mais somente uma opressão de fora para dentro como ocorrera anteriormente, ou seja, Europa à América, mas isso é visto entre o próprio povo, por falta de uma consciência de classe.

Junto com a pobreza socioeconômica há também a pobreza cultural, que é igualmente difícil e pesada. Há opressão e discriminação racial, étnica e sexual. Além disso, é comum que muitas mulheres e povos indígenas enfrentem maiores dificuldades ao longo da vida devido ao seu gênero e à sua origem. Essa dificuldade a mais depende da realidade socioeconômica e a exacerba (BINGEMER, 2017, Os pobres como sujeito e método)

Esses fatos relatados até aqui, de uma opressão europeia e uma continuação desse sentimento/espírito em meio e dentro do povo, deve levar à compreensão do que Jessé Souza chama (embora esteja falando especificamente do Brasil, aplica-se a América Latina) de herança escravocrata. Um exemplo disso é sua afirmação de que o Brasil adentrou o século XX em meio à continuação de padrões valorativos herdadas sob uma máscara moderna do escravismo (SOUZA, 2017).

Esta realidade perpassa a $\mathrm{AL}$, sendo causador de cada vez mais opressão e injustiça. Fazendo uma conexão com a pobreza presente no contexto tratado, deve-se lembrar que a pobreza não está ligada à sorte ou à preguiça, contrariando assim, o argumento meritocrático, mas, "é devida a injustiças estruturais que privilegiam poucos enquanto marginalizam muitos" (BINGEMER, 2017). Logo, diante dessas circunstâncias, é preciso lembrar de um dos principais causadores de tamanha injustiça. "O capitalismo se liga mais à cultura brasileira silenciado a sua exploração e permitindo menos resistência a sua brutalidade" (CARVALHO; PY, 2017, p. 359).

A TLA, volta-se para tudo isso com muita preocupação. Souza assevera que a herança escravocrata, é usada para oprimir todas as classes populares (SOUZA, 2017, Os conflitos de classe no Brasil moderno). E aqui jaz, para a TLA, sua principal área de atuação. Dessa forma, assim como Jesus atuou teológica e socialmente em meio a um contexto de opressão e injustiças, é o dever da teologia atuar e procurar mudar essa realidade. Talvez, faça-se necessário uma atualização teológica da afirmação de Paulo Freire, assim, se a teologia não for libertadora, o sonho do oprimido é tornar-se opressor. 
Assim, o porquê da pergunta postulada acima é parcialmente respondido. Em meio a uma sociedade que vivencia constantemente, e de uma certa maneira normalmente, injustiças, opressão, intolerância, racismo, discriminações, feminicídios, entre tantas outros que poderiam ser citados aqui; é crucial em primeiro lugar, uma teologia que esteja primeiramente baseada em Jesus, tanto historicamente como transcendentalmente (não se pode teologizar Jesus sem historizálo, e nem se pode historizá-lo sem teologizá-lo); e em segundo lugar, uma teologia que esteja pronta à aplicar esse Jesus às necessidades de seu contexto político e social.

De tal modo, Alves resume o dever teológico na América Latina: "O elemento primário, do qual ela nasce e para o qual aponta, consiste na política da liberdade em processo, na qual a liberdade para o futuro e a liberdade para a vida devem ser encontradas. Sua significação é profética" (ALVES, 1987, p. 217). Portanto, os desafios de alcançar a autêntica libertação, continuam em meio as TLA's e na sua relação com a sociedade. Por exemplo, embora haja teologia negra, não é visto no Brasil instituições que apoiem deliberadamente o pensamento teológico negro (Carvalho; PY, 2017, p. 362).

\section{Considerações finais}

Maria Bingemer relata que um dos conceitos mais importantes para a TLA é uma teologia enraizada na realidade (BINGEMER, 2017). Como visto anteriormen-te, essa realidade se apresenta em dois níveis: a realidade de Jesus e a realidade do povo latino-americano. Dessa maneira, Jesus e a sociedade atual estão em estreita relação para a TLA. O Jesus histórico que baseia o Cristo, e dessa maneira Jesus Cristo deve ser um Jesus Cristo para as pessoas, aplicado as suas necessidades, especialmente em meio a injustiças vivenciadas na América Latina.

O fato de a TLA relacionar-se com duas realidades impõe a ela um duplo desafio. Primeiramente, discutir Jesus histórico, e especialmente como ponto de partida cristológico, é um desafio imposto constantemente. Dessa forma, é preciso um auto exame de como ela vê, analisa e pesquisa Jesus, e juntamente com isso, é necessário observar os pressupostos que moldam sua visão e consequentemente sua pesquisa sobre Jesus.

Isso acarreta implicações a seu segundo desafio: a aplicação dessa teologia à sociedade. Isso vai desde sua relação com as demais ciências sociais, como as 
implicações que a própria sociedade exige por si mesma. De tal maneira, assim como a auto análise sobre a visão de Jesus deve ser constante, a análise de sua visão das sociedades, deve ser permanente.

Sendo assim, em meio aos seus desafios, é importante observar que a TLA possui importância crucial na luta por uma sociedade melhor. É valido observar também, que como toda teologia, a TLA possui seus erros e acertos, apesar disso, sua necessidade, implicações e contribuições às sociedades, podem ser vistas claramente. Em meio as diversas teologias importantes neste contexto, os desafios continuam sendo imensos.

Por fim, é valido reafirmar a importância e a necessidade da pesquisa do Jesus histórico nos tempos atuais. Essa é uma pesquisa que não se esgota. Quanto mais próximo for possivel chegar em Jesus, não somente em conceito, mas também em práticas, torna-se possivel a visão e a luta por uma sociedade mais justa e menos desigual. Assim, esse Jesus histórico, que está baseado na interdisciplinaridade e é resultado dela, deve ser encorajado, especialmente nos meios teológicos (sejam faculdades ou seminários). É inegável ainda, que a utilização feita pelos teólogos latino-americanos, do Jesus histórico é crucial para o desenvolvimento de uma teologia mais humanitária, de tal modo que, é de importância crucial para a sociedade desigual e injusta de todos os tempos.

\section{Referências bibliográficas}

ALVES, R. Da esperança. Campinas, SP: Papiros, 1987.

BINGEMER, M. C. Teologia Latino-Americana: raízes e ramos. Kindle. Rio de Janeiro;Petrópolis: PUC-Rio; Vozes, 2017.

CARVALHO, C.; PY, F. Teologia da Libertação: História, Temas e Nomes. CrossCur-rents, v. 67, n. 1, Março 2017. p. 340-364.

CROSSAN, J. D. O Jesus histórico: a vida de um camponês judeu no mediterrâneo. Rio de Janeiro: Imago, 1994.

CROSSAN, J. D. O Nascimento do Cristianismo: o que aconteceu nos anos que se seguira à execução de Jesus. São Paulo: Paulinas, 2004.

CUlmanN, O. Cristologia do Novo Testamento. São Paulo: Hagnos, 2008.

DUNN, J. D. G. Jesus Remembered. Cambrigde U. K.: [s.n.], 2003.

GAlEANO, E. As veias abertas da América Latina. Porto Alegre: L\&PM, 2012.

GEERTZ, C. A interpretação das culturas. Rio de Janeiro: LTC, 2008.

GUTIERREZ, G. Teología de la Liberacion: perspectivas. Salamanca: Seguime, 1972. 
HIGUET, E. A. Medellín e o método da teologia da libertação. Estudos da Religião.São Paulo: UMESP, n. 6, 1989. p. 45-74.

HILGERT, P. R. Jesus histórico: ponto de partida da cristologia latino-americana. Petrópolis: Vozes, 1987.

MEIER, J. P. Um Judeu Marginal: repensando o Jesus Histórico. Rio de Janeiro: Imago, 1992.

SCHEWEITZER, A. A busca do Jesus histórico: um estudo crítico de seu progresso. São Paulo: Novo século, 2003.

SCHMITZ, E. D. Conhecimento, Experiência, Ignorância. COENEN, L.; BROWN, C. Dicionário internacional de Teologia do Novo Testamento. São Paulo: Vida Nova, v. $1,2000$.

SEGUNDO, J. L. A História perdida e recuperada de Jesus de Nazaré: dos sinótico a Paulo. São Paulo: Paulus, 1997.

SOBRINO, J. Jesús Cristo en América Latina: su significado para le fe y la cristología. San Salvador: UCA/Editores, 1982.

SOBRINO, J. Jesus Liberador: Lectura histórico-teológica de Jesus de Nazaret. $2^{\text {a }}$. ed. Madrid: Editora Trotta, 1991.

SOUZA, J. A Elite do Atraso: da escravidão à Lava Jato. Kindle. ed. Rio de Janeiro: Leya, 2017.

STEGEMANN, W. Jesus e Seu Tempo. São Lepoldo: Sinodal; EST, 2012.

THEISSEN, G.; MERZ, A. O Jesus Histórico: um manual. São Paulo: Loyola, 2002.

WEGNER, U. Exegese do Novo Testamento: manual de metodologia. $7^{\circ}$ ed. São Leopoldo: Sinodal, 1998.

\footnotetext{
1 A partir daqui se usará essa sigla como abreviação de "teologia latino-americana". É importante ressaltar que TLA é entendida nesse artigo, como as diversas teologias produzidas, aprofundadas e que possuem suas características em relação ao contexto latinoamericano. Assim, TLA não se refere aqui à uma teologia específica, mas as diversas teologias desenvolvidas por teólogos latino-americanos em intrínseca relação com o contexto social, econômico e político da América Latina.

2 Para uma discussão sobre a utilização do termo Jesus real cf. Stegemann, 2012. p. 115-124; Meier, 1992.

${ }^{3}$ Seguiremos a divisão de três momentos da pesquisa sobre o Jesus histórico, first, second e third quest. Contudo, reconhecemos as demais alternativas para a divisão das fases dessa pesquisa. Cf. Stegemann, 2012.

${ }^{4}$ Interessante ressaltar que para esses autores, nesse periodo existiram duas fases diferentes de pesquisa.

${ }^{5}$ Compreendemos que a abrangência e a discussão das fases da pesquisa sobre o Jesus histórico são mais profundas e abrangentes do que está resumido nos parágrafos deste artigo, envolvendo temas como "liberalismo", "nazismo", "escatologia", etc. Assim, para aprofundamento nessas pesquisas cf. Scheweitzer, 2003; Stegmann, 2012.
} 
6 Para aprofundamento nesses critérios cf. Theissen; Merz, 2002; Stegemann, 2002.

${ }^{7}$ Dunn, 2003, p. 126. "[...] the 'historical Jesus' is properly speaking a nineteenth- and twentieth-century construction using the data provided by the Synoptic tradition, not Jesus back then and not a figure in history whom we can realistically use to critique the portrayal of Jesus in the Synoptic tradition" (grifo nosso).

${ }^{8}$ Stegemann, 2012, p. 129. (Acréscimo próprio).

${ }^{9}$ Sobrino, 1991. Esse livro se faz importante nessa pesquisa, pois Sobrino resume e proporciona pontos fundamentais para essa discussão.

10 SOBRINO, 1991, p. 61. "Afirmar que Jesús es el Cristo, que es expresión de lo verdaderamente divino y verdaderamente humano, son afirmaciones-límite que, por su naturaleza, exigen un camino del conocimiento". (Tradução nossa).

11 SOBRINO, 1982. p. 128.

12 Esta visão aprofunda-se especialmente quando se entende o Deus YWHW no AT, e sua ação em Jesus no NT, como ações que buscavam justiça social, sendo assim, Deus é um Deus de justiça social. Para aprofundamento no assunto cf. Crossan, 2004.p. 221-250.

Recebido em 12/02/2021

Aceito para publicação em 27/03/2021 